\title{
CAMUS \\ Y EL MISTERIO \\ DE LOS CISNES
}

Tomás Voticky*

RESUMEN: A cincuenta años de la muerte de Albert Camus, un sutil homenaje que incluye las vinculaciones del premio Nobel de Literatura con la física cuántica, las burbujas financieras y la estadística, en particular, con su tesis medular sobre el absurdo.

yose

ABSTRACT: On the fiftieth anniversary of this Nobel Literature Prize winner's death, we pay him homage by describing how he incorporated quantum physics, financial bubbles, and Statistics in his core theory of absurdity.

Palabras ClaVE: Camus, cincuentenario, Bohr, Taleb, Ponzi, siglo XXI.

KEYwords: Camus, fiftieth anniversary, Bohr, Taleb, Ponzi, twenty-first century.

RECEPCIÓN: 26 de agosto de 2010.

APROBACIÓN: 30 de septiembre de 2010.

* Economista. 
La reproducción total o parcial de este artículo se podrá hacer si el ITAM otorga la autorización previamente por escrito. 


\section{CAMUS \\ Y EL MISTERIO \\ DE LOS CINES}

Este hombre no es de ayer ni es de mañana, sino de nunca; de la cepa hispana, no es el fruto maduro ni podrido, es una fruta vana.

Antonio Machado

\section{$\mathrm{E}_{1}$ año pasado se cumplieron 50 años}

de la muerte de Albert Camus en un accidente automovilístico. La muerte prematura fue el corolario de una vida con una intensidad y proyección poco frecuentes en un intelectual, pero que acabó como toda vida. Una inteligencia auténtica y sin concesiones que conoció el éxito temprano; fue miembro del partido comunista; recibió una condecoración por participar en la resistencia francesa y el Premio Nobel de Literatura, para verse posteriormente condenado al ostracismo por su renuencia a transigir con la praxis comunista y a seguir las corrientes ideológicas en boga, como lo hicieron muchos de los intelectuales de la época.

El trabajo de Camus no desarrolla un sistema de conocimiento integrador o taxonomía de objetos de estudio, ni la prescripción de un principio unificador o fundamento, sino que fue precursor de una nueva relación entre el hombre y el mundo, en la cual se invierten los términos del conocimiento que prevalecían desde el racionalismo. Sus principales aportaciones parecen haber sido reivindicadas por las bases metodológicas independientes en la Física y propuestas económicas independientes (como las teorías post-económicas del mercado que buscan explicar las crisis recurrentes sustituyendo el supuesto del equilibrio en los mercados o los ciclos económicos por el concepto de una nueva normalidad, con volatilidad e incertidumbre como fenómenos permanentes).

La conciencia del absurdo, tema fundamental en Camus, no aparece en forma meramente especulativa en su obra, sino que se manifiesta 
TOMÁS VOTICKY

como el sentimiento más natural frente a su experiencia propia: se vio afectado en su juventud por la tuberculosis, lo que le impediría posteriormente presentar su examen de licenciatura. El absurdo se manifiesta inicialmente en un plano universal, como enajenación del sujeto frente a la maquinaria de la Segunda guerra mundial y los regímenes totalitarios del siglo XX; luego experimenta un desplazamiento progresivo hacia lo individual, con el régimen de Vichy en Francia, tras la firma del armisticio con la Alemania Nazi. Después del fallido desembarco de las tropas estadounidenses y británicas al este y oeste de Argelia en noviembre de 1942, los alemanes invadieron la región de Vychi, donde se encontraba Camus en aquella época, quedando imposibilitado para regresar a Argelia para reunirse con Francine, encontrándose sin ingresos y sin poder colaborar en ningún periódico.

Durante el último año, una serie de acontecimientos que sobrevinieron en forma abrupta, me han llevado a recordar los textos de Albert Camus en forma recurrente: el brote de influenza humana que se dio a finales de abril del 2009; la crisis en los mercados financieros por instrumentos respaldados por hipotecas sub-prime y, recientemente, la crisis de deuda griega. A pesar de que el libro que acude inmediatamente a la mente es La Peste, en ambos casos, la aparición súbita de fenómenos altamente disruptivos como algo exógeno que afecta desde nuestra convivencia cotidiana hasta nuestro empleo, hacen reflexionar sobre El mito de Sísifo.

Sísifo, la imagen mítica de la repetición, regresa a la mente continuamente como la roca que el infeliz mortal incansablemente hacía subir la cuesta de una montaña para volver a caer incesantemente. Hace poco se han publicado numerosos artículos sobre la recurrencia de las burbujas en los mercados financieros, como los tulipanes en Holanda, las Dot com en el 2000 y la burbuja hipotecaria en el 2009, con diversos modelos matemáticos y comportacionales que modelan cómo los inversionistas se suben a una ola especulativa en forma similar a una pirámide de dinero o esquema Ponzi. A medida que las teorías basadas en expectativas racionales o mercados financieros eficientes (que incorporan toda información disponible en el precio actual de un activo) van 
perdiendo credibilidad, surgen teorías alternativas como la de Nassim Taleb, autor de Black Swan: The Impact of the Highly Improbable.

La alegoría del mito de Sísifo ofrece una explicación estructural a esta resuelta persistencia de los inversionistas a arruinarse por imitación o ambición. La ineludible necesidad de la repetición en el hombre, resonancia de la caída bíblica, parece llevar a un donjuanismo financiero que, al igual que el obstinado burlador, constituye el mito del triunfador del momento, por medio de la repetida promesa incumplida.

La explicación alternativa que se deriva de El Mito de Sísifo, es que el hombre está destinado a trabajar incansablemente en proyectos que, invariablemente, terminan por venirse abajo:

Los dioses condenaron a Sísifo a empujar eternamente una roca hasta lo alto de una montaña, desde donde la piedra volvía a caer por su propio peso. Pensaron, con cierta razón, que no hay castigo más terrible que el trabajo inútil y sin esperanza.

Se habrá comprendido ya que Sísifo es el héroe absurdo. Lo es tanto por sus pasiones como por su tormento. Su desprecio de los dioses, su odio a la muerte y su pasión por la vida le valieron ese suplicio indecible en el que todo el ser se dedica a no acabar nada. Es el precio que hay que pagar por las pasiones de esta tierra. ${ }^{1}$

\section{Aleatoriedad o contingencia}

Las ideas de Camus se desarrollaron en forma paralela a los planteamientos, radicales en su tiempo, sobre la física cuántica de Niels Bohr, que cuestionaban la aplicación de nuestras categorías clásicas sobre la realidad al mundo subatómico, conduciendo a la introducción del concepto de probabilidad en la naturaleza por medio de la función de onda. Lo anterior llevaría a Einstein a replicar: Dios no juega a los dados.

La presencia de procesos aleatorios en la naturaleza no es algo extraño para la ciencia moderna. La teoría de la evolución considera la presencia de variación genética aleatoria como la fuente de cambio no direccio-

\footnotetext{
${ }^{1}$ Albert Camus, El mito de Sísifo, 2009, Madrid, Alianza Editorial.
} 
TOMÁS VOTICKY

nal para la selección de especies. Este cambio se verifica gradualmente, como desviaciones mínimas respecto a la media. En caso contrario se trata de una mutación o la extinción de una especie por una catástrofe natural. Gran parte del manejo de la probabilidad en las ciencias naturales y sociales se basa en la curva normal.

La inferencia estadística procede más o menos de la siguiente manera: tomemos un grupo numeroso de personas, digamos 5 millones de individuos. Ahora dividámoslo en diez grupos seleccionando a los individuos al azar. Tomemos una serie de medidas como el porcentaje de mujeres y hombres, peso promedio, altura promedio, etc. Ahora comparemos los resultados entre los 10 grupos: cada una de estas métricas es igual, con un reducido rango de error, a la de cualquiera de los otros grupos y, además, a las medidas para el total (5 millones). Este parece ser el método más seguro para sacar conclusiones yendo de lo particular a lo general.

La mayor parte de los métodos estadísticos parten del supuesto de la distribución normal, así como en forma implícita o explícita, de que observaciones pasadas sirven para predecir el futuro. Del primer supuesto, el Sr. Taleb se ha encargado de comentarlo ampliamente. Del segundo, la explicación determinista parecería de aplicación problemática en las ciencias sociales, aunque pudiera ser consistente para las ciencias naturales (con la duda de si explica procesos evolutivos). En la mecánica cuántica, el supuesto que las condiciones iniciales determinan la evolución del proceso requiere de sutilezas metodológicas para evitar soluciones infinitas y la superposición de estados cuestiona el concepto de causalidad clásica.

Nassim Taleb narra en su libro cómo, hasta antes del descubrimiento del cisne negro en Australia, todo el mundo pensaba que todos los cisnes eran blancos. Esto había sido confirmado por millones de observaciones de cisnes blancos. En forma más general, Karl Popper cuestionaba el proceso de inducción, esto es, el ir de lo particular a lo general, o inferir enunciados universales partiendo de enunciados singulares, ya que, como en el caso del cisne negro, una sola observación puede invalidar el enunciado universal. 


\section{El absurdo}

Camus formula el concepto del absurdo como una fractura entre el mundo y mi espíritu, a partir de la lógica de que el mundo no se puede explicar, con el consecuente divorcio entre el hombre y su vida.

La existencia humana que concluye o desemboca en la muerte, y nada más, no encuentra un motivo válido para la esperanza. Esta interpretación difiere de la concepción de la muerte como la posibilidad de la absoluta imposibilidad del "ser ahí" de Heidegger. Albert Camus afirma sin ningún asomo de racionalización psicológica: "Un hombre que adquiere conciencia de lo absurdo queda ligado a ello para siempre. Un hombre sin esperanza y consciente de no tenerla no pertenece ya al porvenir".

Una existencia que se encuentra rebasada por su sentido, en el sentido de un destino trágico, o por un universo inconmensurable respecto al hombre. Esto último alude a la desproporción entre la magnitud del universo y la razón finita.

Ahora bien, aunque a primera vista esta intuición del absurdo parece natural, podemos cuestionar: ¿Por qué implica esta contradicción entre las expectativas del hombre y el devenir del mundo un absurdo? ¿Acaso no es lógico que el mundo o el universo entero se comportara de acuerdo a las leyes y designios de la razón humana? Un universo a la medida del ser humano es lo que tiene sentido.

Creo que el argumento de que el mundo o el universo entero se rige por las leyes de la razón sólo tiene consistencia lógica si se refiere a una razón divina, pero excluyendo el concepto de un Dios, no tiene el carácter de necesario.

El absurdo es una categoría del pensamiento humano, de la misma manera que lo es el concepto de las leyes naturales.

\section{Relevancia de Albert Camus en el siglo XXI}

¿Es Albert Camus un pensador relevante para la historia de la filosofía? En el libro Historia del pensamiento filosófico y científico, volumen III (del Romanticismo hasta hoy) de Giovanni Reale y Dario Antiseri, sólo 
TOMÁS VOTICKY

se le menciona brevemente con relación a otros autores existencialistas. Camus ganó el Premio Nobel de Literatura en 1957. Cabe preguntar, ¿qué significa el hecho poco común de ser galardonado un escritor cuya temática es eminentemente filosófica con el Premio Nobel de Literatura, para el significado de su obra? ¿Pertenece ésta a la literatura o la filosofía? El hecho de que se le haya reconocido abiertamente con un premio universal y de alguna manera se le haya escamoteado el reconocimiento en el terreno de la filosofía, permanece un misterio.

Las tres obras que figuran en su diario como los tres absurdos: $E l$ extranjero, El mito de Sísifo y Calígula, constituyen el núcleo originario de su pensamiento. Después de un largo periodo iba venir El hombre rebelde, que lo marcaría en forma similar al proceso desencadenado contra Ludvik, en La Broma de Milan Kundera, pero en forma opuesta: si el pecado del personaje del libro de Kundera es una ligereza contra el marxismo al lanzar la frase "el optimismo es el opio del pueblo", Camus peca al no hacer concesiones pragmáticas en su denuncia del estalinismo. Ya no habría marcha atrás en el proceso de alienación dual desencadenado: por una parte, su voluntad se rebela y se obstina en mantener la afirmación inicial sin retractarse, y por otra, se echa a andar una maquinaria burocrática que los aislaría progresivamente.

Resulta indicativo el que las partes más relevantes del pensamiento de Camus se encuentren cifradas en novelas, en lugar de ensayos, aunque esto puede deberse a lo que Milan Kundera ve en la naturaleza íntima de la novela, en el sentido en que cada acontecimiento pierde su carácter concreto al ser narrado, convirtiéndose en silueta:

La narración es un recuerdo, por tanto un resumen, una simplificación, una abstracción.

El arte de la novela ha encontrado la respuesta: presentando el pasado en escenas. La escena, incluso contada en pasado gramatical, es, ontológicamente el presente. ${ }^{2}$

${ }^{2}$ Milan Kundera, El Telón, 2005, México, Tusquets Editores. 
De esta manera la novela, al igual que el mito, ha sido con frecuencia el vehículo para exponer argumentos filosóficos prescindiendo de un lenguaje formal.

Bien pudiera ser que el rompimiento con Sartre en 1952 contribuyera a esta omisión en la historia del pensamiento. A este último siempre se le ha atribuido la fundación del existencialismo. Probablemente el haberse mantenido al margen de las corrientes filosóficas de la época, el marxismo y el existencialismo, pudo haber trastocado su papel en la historia de la filosofía. Esto hace reflexionar sobre el proceso de génesis de la ciencia, el proceso mediante el cual los miembros de comunidades científicas se nutren con las ideas de otros, pero al mismo tiempo sancionan y excluyen a los que no se amoldan a la corriente principal. El reconocimiento finalmente debe venir de otros individuos o de una comunidad científica o académica. Sin embargo, a pesar de la naturaleza social de conocimiento científico o profesionalizado, reconocimiento y verdad suelen encontrarse distanciados en el tiempo.

Al retomar la idea directora de Camus sobre filosofar sobre el absurdo, no quiero polemizar de más, dada la ya de por sí tirante relación entre la filosofía y las ciencias, pero esta concepción contrasta con la posición de Wittgenstein en torno a que los problemas filosóficos no son más que pseudo-problemas surgidos en torno a una inadecuada lingüística. Así mismo, se sitúa en un sistema de coordenadas completamente ortogonal al de la lógica formal y la teoría semántica moderna.

Camus toma partido con Nietzsche afirmando que no hay hechos, sino interpretaciones de hechos:

El deseo profundo del espíritu mismo en sus operaciones más evolucionadas se une al sentimiento inconsciente del hombre ante su universo: es exigencia de familiaridad, apetito de claridad. Para un hombre, comprender el mundo es reducirlo a lo humano, marcarlo con su sello. El universo del gato no es el universo del oso hormiguero. La perogrullada "todo pensamiento es antropomórfico" no tiene otro sentido. Del mismo modo, el espíritu que trata de comprender la realidad no puede considerarse satisfecho salvo si la reduce a términos de pensamiento. 
TOMÁS VOTICKY

Esta postura contrasta con la versión sobre-simplificada del mundo como espejo, la teoría del lenguaje que formula Wittgenstein, según la cual la substancia del mundo está constituida por objetos, que se encuentran en correspondencia con el conjunto de nombres que articulan una proposición.

El mito de Sísifo surge como una alegoría del desafío del hombre a sus dioses en la mitología griega. Su castigo es la condena a un destino absurdo, un continuo ocuparse sin sentido (la "Cura" en Heiddegger). El recurso a la imagen mítica en pleno siglo XX, en oposición al iluminismo de la razón que inició con la Ilustración, plantea un repliegue ante el ideal del progreso en Occidente. El paradigma de las leyes naturales es antiguo; en la filosofía escolástica se formulaba como una prescripción jurídica que gobierna a un ciudadano en una comunidad; como una ley moral que gobierna al ser racional, cuya razón estaba ordenada a la razón divina por participación en la ley eterna. La extensión de la ley moral a la naturaleza se hace por analogía (un esquema muy utilizado por Santo Tomás de Aquino). Este orden universal era inteligible para el hombre, y la piedra angular era Dios. Al remover a Dios pretendiendo conservar el resto del edificio, el sistema pierde toda su estabilidad. Y es que ya no es posible aplicar satisfactoriamente el criterio de demarcación a la invariancia de las leyes naturales, ya que no es posible demostrar que el enunciado: las leyes naturales son invariantes (podemos incluso decir: de un sistema a otro) es observable.

La razón concluyó negando la existencia de Dios por no poderse plantear en enunciados observables, esto es, no poder verificar su no existencia en los términos propios de la razón.

Dos posiciones fundamentales han surgido en la actualidad alrededor de la tesis medular de Camus, ilustradas por dos autores franceses contemporáneos: Jean Gitton y Michel Houellebecq.

Michel Houellebecq ${ }^{3}$ hace una crítica de la opción hedonista-libidinal impulsada por los órganos de prensa liberales norteamericanos en los años 60. En lo que se refiere al sentido de la existencia humana, efectúa un proceso de deconstrucción del concepto del yo haciendo una analo-

${ }^{3}$ Michel Houllebecq, Las partículas elementales, 2008, Barcelona, Editorial Anagrama. 
gía con las historias de Griffiths en la física, donde a partir de un subconjunto de medidas se puede armar una historia lógicamente coherente, aunque no verdadera. Retomando el formato de la novela de Kundera, nuestra conciencia del yo nos permite reconstruir una historia coherente a partir de nuestros propios recuerdos: una existencia testimonial unívoca sumergida en una ontología de objetos y categorías. La posterior mutación metafísica operada por la ciencia moderna conlleva la individuación, vanidad, odio y el deseo.

Para el pensamiento moderno no tiene sentido la cuestión que plantea Camus sobre el rompimiento entre el yo y el mundo. El yo es sólo un producto de nuestra imaginación, una construcción de la razón, un ordenamiento en retrospectiva de nuestras vivencias. Nótense las coincidencias: primero con Milan Kundera en cuanto a la transmutación del recuerdo en el presente ontológico por medio de la narración; y luego con el tercer criterio de Nassim Taleb para describir un cisne negro: la explicación de hechos que salen fuera del marco de una teoría o modelo, en retrospectiva, haciéndolo explicable y predecible después de sucedido.

Como dice Bruno, uno de los protagonistas en Las partículas elementales: "Me gustaría creer que el yo es una ilusión; pero eso no impide que sea una ilusión dolorosa..."

La reflexión en torno al absurdo que hace Jean Gitton se desarrolla en respuesta a una pregunta directa en su conversación con François Miterrand, quien le pidió explicarle en diez minutos el sentido de la vida, con esta afirmación: aparentemente todo es absurdo, sino, todo es un misterio.

El absurdo y el misterio son dos soluciones posibles para la experiencia de la vida. Absurdo y misterio son dos polos opuestos entre los cuales oscila el pensamiento.

Frente a la objeción de los que se oponen al sentido del misterio, esgrimiendo la imposibilidad de la verificación, o la falsabilidad en términos de Popper (que sea posible refutar una determinada sentencia por la experiencia), concluye que la decisión está sujeta a la posibilidad inminente de una última verificación, una contrastación radical de la que no hay marcha atrás: la muerte. 
TOMÁS VOTICKY

En términos de Camus, el salto del absurdo al misterio, constituye lo que denomina el "suicidio existencial", en cuanto el movimiento por el cual el pensamiento se niega a sí mismo y tiende a superarse en lo que es su negación.

En todo caso, la posición existencial frente al absurdo implica una decisión. Y al respecto cabe preguntar: ¿en qué momento es válido calificar una decisión como buena o mala, antes o después de conocer su resultado? 